\title{
Do platelet indices play a role in assessing the severity of pre-eclampsia and eclampsia?
}

\author{
Priyamvada Singhal $^{1}$, Vishal Agrawal ${ }^{2}$, Narayan S Ingole ${ }^{3}$, Nitin Gangane ${ }^{3}$ \\ ${ }^{l}$ Department of Pathology, Subharti Medical College, Meerut, U.P, India \\ ${ }^{2}$ Radiodiagnosis, Health care imaging center, Meerut, U.P, India \\ ${ }^{3}$ Department of Pathology, Mahatma Gandhi Institute of Medical Sciences, Maharashtra, India
}

\section{Keywords: \\ Eclampsia; \\ Platelet count; \\ Platelet indices; \\ Pre-eclampsia}

\begin{abstract}
Background: Pre-eclampsia and eclampsia is a multisystem disorder affecting approximately $2-7 \%$ of all pregnancies and is a significant cause of maternal and fetal morbidity and mortality. Many hemostatic abnormalities have been reported in association with hypertensive disorder of pregnancy. We conducted this prospective case-control study to assess and analyze the platelet parameters in 3rd-trimester normotensives, pre-eclamptic, and eclamptic pregnant women.

Materials and Methods: This study was conducted in the hematology division of the Department of Pathology, in a rural population-based medical institute over 2 years. In all subjects (cases and controls) $2 \mathrm{ml}$ of blood sample was collected in EDTA vials for platelet counts and platelet indices. The blood samples were run on an automated blood cell counter (Beckman coulter) within 2 hours of collection. The data obtained were tabulated and statistical analyses were performed.

Results: The mean platelet count was significantly decreased in cases as compared to controls with increased frequency of thrombocytopenia associated with progression of the disease. Platelet indices, mean platelet volume, and platelet distribution width were increased, whereas the plateletcrit was decreased in cases as compared to the controls. However, the statistically significant difference was found only in platelet distribution width and plateletcrit.

Conclusions: We concluded that platelet indices like platelet distribution width and plateletcrit can be useful along with platelet count in early detection of pre-eclampsia and eclampsia instead of relying on platelet count alone.
\end{abstract}

\section{Correspondence:}

Dr. Priyamvada Singhal

Department of Pathology

Subharti Medical College, Meerut, U.P, India

Email: priyamvadasinghal15@gmail.com

ORCID: https://orchid.org/0000-0001-9867-0747

Received : $15^{\text {th }}$ September $2020 ;$ Accepted $: 22^{\text {nd }}$ Feburary 2021

Citation: Singhal P, Agrawal V, Ingole NS, Gangane N. Do Platelet Indices play a role in assessing the severity of Pre-eclampsia and Eclampsia? Journal of Pathology of Nepal. 2021;11(2): 1790-5. DOI: $10.3126 /$ jpn.v11i2.31241

Copyright: This is an open-access article distributed under the terms of the Creative Commons Attribution 4.0 International License, which permits unrestricted use, distribution, and reproduction in any medium, provided the original author and source are credited.

\section{INTRODUCTION}

Hypertensive disorders during pregnancy are the second leading cause, after embolism, of maternal mortality in the United States, accounting for almost $15 \%$ of such deaths. Hypertension during pregnancy may lead to many maternal complications including abruptio placentae, disseminated intravascular coagulation (DIC), cerebral hemorrhage, hepatic failure, and acute renal failure. ${ }^{1}$ Studies have suggested that placental vascular under perfusion, maternal endothelial damage, and increased vascular permeability has been contributory to the pathophysiology of the disease. ${ }^{2}$ 
Many hemostatic abnormalities have been reported in association with hypertensive disorder of pregnancy. Thrombocytopenia is the most common of these abnormalities. ${ }^{3,4}$ In addition to changes in absolute platelet numbers, the platelets also appear to circulate in a more activated state which is reflected in the changes in platelet indices in hypertensive disorders of pregnancy. Many studies have been done to investigate the changes in platelet indices. Also, these changes sometimes appear 4-6 weeks before the significant rise in blood pressure. ${ }^{5}$

Pre-eclampsia and eclampsia of varying degrees of severity form a considerable portion of admissions in our hospital. In these patients, varying degrees of DIC can contribute significantly to morbidity and sometimes even to mortality. This study was thus conducted in a rural population-based medical institute to assess the significance of platelet counts and platelet parameters to the severity of pre-eclampsia and eclampsia.

\section{MATERIALS AND METHODS}

This study was a prospective case-control study conducted in the hematology division of the Department of Pathology, in a rural population-based medical institute for 2 years. The study was approved by the Institutional Research ethical committee. The total sample size was 160, comprising of two groups of 80 cases and 80 controls. All the blood samples for the cases were obtained from the pregnant women in 3rd trimester of gestation admitted in the obstetric ward and diagnosed as pre-eclamptic or eclamptic patients according to the standard clinical criteria published by the American College of Obstetrics and Gynaecology $(2002)^{6}$ whereas randomly selected uncomplicated normotensive pregnant women attending obstetric OPD served as controls.

Inclusion criteria consisted of pregnant women between 28 to 40 weeks of gestation with pre-eclampsia and eclampsia with having minimum criteria of (1) BP $\geq 140 / 90$ $\mathrm{mm} \mathrm{Hg}$ after 20 weeks of gestation and (2) Proteinuria $\geq$ $300 \mathrm{mg} / 24 \mathrm{hrs}$ or $\geq 1+$ with a dipstick.

Exclusion criteria consisted of pregnant women with known bleeding disorders, liver disease, abruptio placentae, intrauterine fetal death, trauma, any associated inflammatory disease or sepsis, any associated malignancy, in labor, and on anticoagulant therapy.

All the cases were sub-grouped into mild pre-eclampsia,

\section{Table 1: Grading of pre-eclampsia}

\begin{tabular}{lcc}
\hline Abnormality & Mild Pre-eclampsia & Severe Pre-eclampsia \\
\hline $\begin{array}{l}\text { Diastolic Blood } \\
\text { Pressure }\end{array}$ & $<110 \mathrm{~mm} \mathrm{Hg}$ & $\geq 110 \mathrm{~mm} \mathrm{Hg}$ \\
\hline $\begin{array}{l}\text { Systolic Blood } \\
\text { Pressure }\end{array}$ & $<160 \mathrm{~mm} \mathrm{Hg}$ & $\geq 160 \mathrm{~mm} \mathrm{Hg}$ \\
\hline Proteinuria & $\leq 2+$ & $\geq 3+$ \\
\hline
\end{tabular}

DOI: 10.3126/jpn.v11i2.31241 severe pre-eclampsia, and eclampsia; the severity of preeclampsia was graded into two categories. (Table 1)

In all the subjects, informed consent was obtained and 2 $\mathrm{ml}$ venous blood samples were collected in EDTA $(0.25 \mathrm{mg}$ / $\mathrm{ml}$ ) vial for platelet count and platelet parameters i.emean platelet volume(MPV), Platelet distribution width (PDW), Plateletcrit (Pct). The blood sample was run on Beckman Coulter make (18 parameters) automated blood cell counter within 2 hours of collection.

Thrombocytopenia was defined as platelet count $<150$ x $10^{9} / \mathrm{L}$ and platelet indices - MPV, PDW and Pct were considered abnormal if $>11 \mathrm{fl},>17.1 \mathrm{fl}$ and $<0.360 \%$ respectively.

The data thus obtained was tabulated and statistical analyses were performed by using student's unpaired t-test, one-way ANOVA, and Tukey test. The student's unpaired t-test was used to compare various parameters between the case and control groups. One-way ANOVA and Tukey test were used to make multiple comparisons between groups and subgroups (control, mild PE, severe PE \& eclampsia). Statistical significance was considered at $\mathrm{p}<0.05$.

\section{RESULTS}

We studied platelet count, MPV, PDW, and Pct in total of 80 cases of pre-eclampsia and eclampsia in the 3rd trimester of pregnancy. It included $21(26.25 \%)$ cases of mild preeclampsia, 28 (35\%) cases of severe pre-eclampsia, and 31 (38.75\%) cases of eclampsia. The age distribution of the cases revealed maximum of $39(48.75 \%)$ cases in the range of 20-24 years. (Table 2)

Statistically, (Student's unpaired t-test) the differences in gestational age between cases and control were insignificant ( $>0.05$ ) except for the difference between the gestational age of eclampsia and severe pre-eclampsia which was significant $(p=0.015,<0.05)$. (Table 3)The difference in parity in cases and controls was found statistically insignificant $(p=0.88,>0.05)$. When compared among the subgroups of cases (one-way ANOVA and Tukey test), severe pre-eclampsia and eclampsia were found to be more common in primiparous women as compared to that in mild pre-eclampsia and statistically, this difference was found to be significant $(\mathrm{p}<0.05)$.

By using student's unpaired t test statistically significant difference was noted in platelet count between case and control groups $(\mathrm{p}$-value $=0.000,<0.05)$. On using one way ANOVA and Tukey test, statistically significant difference was seen between control and severe pre-eclampsia $(\mathrm{p}=0.035$, $<0.05)$, control and eclampsia $(\mathrm{p}=0.000,<0.05)$ and mild pre-eclampsia and eclampsia $(\mathrm{p}=0.007,<0.05)$. However, no significant difference was found between control and mild pre-eclampsia $(\mathrm{p}=0.961,>0.05)$, mild pre-eclampsia and severe pre-eclampsia $(\mathrm{p}=0.348,>0.05)$ and severe pre- 
Table 2. Age-wise distribution of patients in cases and controls

\begin{tabular}{|c|c|c|c|c|c|}
\hline \multirow[b]{2}{*}{ Age group (Years) } & \multirow[b]{2}{*}{ Control } & \multicolumn{4}{|c|}{ Number of cases (Percentage) } \\
\hline & & Mild PE (\%) & Severe PE $(\%)$ & Eclampsia (\%) & Total Cases (\%) \\
\hline 20-24 & $38(47.5)$ & 6 & 14 & 19 & $39(48.75)$ \\
\hline $25-29$ & $33(41.25)$ & 10 & 11 & 8 & $29(36.25)$ \\
\hline $30-34$ & $6(7.5)$ & 5 & 2 & 4 & $11(13.75)$ \\
\hline $35-40$ & $3(3.75)$ & 0 & 1 & 0 & $1(1.25)$ \\
\hline Total & $80(100)$ & $21(26.25)$ & $28(35)$ & $31(38.75)$ & $80(100)$ \\
\hline Mean Age \pm SD & $25.14 \pm 3.68$ & $25.86 \pm 3.90$ & $25.00 \pm 3.41$ & $23.58 \pm 3.54$ & $24.68 \pm 3.67$ \\
\hline Range & $20-35$ & $20-34$ & $20-35$ & $20-31$ & $20-35$ \\
\hline
\end{tabular}

*PE: pre-eclampsia

Table 3: Distribution of cases and controls with gestational age and parity

\begin{tabular}{lcccc}
\hline Diagnosis & No. of patients & Gestational age & \multicolumn{2}{c}{ Parity } \\
\hline Cases & 80 & Mean \pm SD & Primi (\%) & Multi (\%) \\
\hline a. Mild PE & 21 & $33.85 \pm 4.10$ & $49(61.25)$ & $31(38.75)$ \\
\hline b. Severe PE & 28 & $33.98 \pm 3.32$ & $10(47.62)$ & $11(52.38)$ \\
\hline c. Eclampsia & 31 & $32.22 \pm 3.87$ & $22(70.97)$ & $11(39.29)$ \\
\hline Controls & 80 & $35.24 \pm 4.34$ & $50(62.5)$ & $9(29.03)$ \\
\hline & & $34.56 \pm 3.73$ & & $30(37.5)$ \\
\hline
\end{tabular}

*PE: pre-eclampsia

Table 4: Mean platelet count and thrombocytopenia in cases and controls

\begin{tabular}{|c|c|c|c|c|}
\hline \multirow{2}{*}{ Diagnosis } & \multirow{2}{*}{ No. of patients } & \multicolumn{2}{|c|}{ Platelet count (x 109/L) } & \multirow{2}{*}{$\begin{array}{c}\text { Thrombocytopenia } \\
\text { (\%) }\end{array}$} \\
\hline & & Range & Mean \pm SD & \\
\hline Cases & 80 & $16-430$ & $174.30 \pm 87.56$ & $36(45)$ \\
\hline a. Mild PE & 21 & $97-386$ & $214.9 \pm 80.87$ & $5(6.25)$ \\
\hline b. Severe PE & 28 & $16-430$ & $177.96 \pm 100.88$ & $13(16.25)$ \\
\hline c. Eclampsia & 31 & $21.2-285$ & $143.49 \pm 67.23$ & $18(22.5)$ \\
\hline Controls & 80 & $80-414$ & $224.19 \pm 69.81$ & $12(15)$ \\
\hline
\end{tabular}

*PE: pre-eclampsia

Table 5: Platelet parameters (MPV, PDW and Pct) in cases and controls

\begin{tabular}{lccccccc}
\hline Diagnosis & No. of patients & \multicolumn{2}{c}{ MPV $(\mathbf{f l})$} & \multicolumn{2}{c}{ PDW (fl) } & \multicolumn{2}{c}{ Pct (\%) } \\
\cline { 1 - 2 } & & Range & Mean \pm SD & Range & Mean \pm SD & Range & Mean \pm SD \\
Cases & 80 & $6.9-12.8$ & $8.96 \pm 1.33$ & $11.8-19.4$ & $17.46 \pm 1.19$ & $0.03-0.98$ & $0.19 \pm 0.14$ \\
\hdashline a. Mild PE & 21 & $7.1-10.9$ & $8.72 \pm 1.06$ & $11.8-19$ & $16.94 \pm 1.64$ & $0.12-0.31$ & $0.20 \pm 0.06$ \\
\hdashline b. Severe PE & 28 & $6.9-11.9$ & $8.85 \pm 1.23$ & $15.3-19.3$ & $17.24 \pm 1.01$ & $0.07-0.96$ & $0.19 \pm 0.17$ \\
\hdashline c. Eclampsia & 31 & $6.9-12.8$ & $9.21 \pm 1.56$ & $16.8-19.6$ & $18.03 \pm 0.69$ & $0.03-0.98$ & $0.17 \pm 0.16$ \\
\hdashline Controls & 80 & $4.1-13$ & $8.62 \pm 1.29$ & $8.2-20.40$ & $16.62 \pm 1.82$ & $0.13-0.33$ & $0.22 \pm 0.03$ \\
\hline
\end{tabular}

*PE: pre-eclampsia

Table 6: Comparison of platelet counts in different studies

\begin{tabular}{|c|c|c|c|c|}
\hline \multirow{2}{*}{ Author } & \multicolumn{4}{|c|}{ Platelet counts (x 109/L) } \\
\hline & Control & Mild PE & Severe PE & Eclampsia \\
\hline Srivastava et al ${ }^{17}$ & 194.4 & 179.7 & 164.2 & 152.6 \\
\hline Jambhulkar et al ${ }^{18}$ & 238 & 230 & 170 & 151 \\
\hline Vrunda and Shaila ${ }^{19}$ & 220 & 200 & 140 & 130 \\
\hline Mohammed et $\mathrm{al}^{10}$ & 242.9 & 209 & 155 & 121 \\
\hline Chauhan et $\mathrm{al}^{20}$ & $222.93 \pm 97.94$ & $173.33 \pm 25.91$ & $145.04 \pm 23.76$ & $121.05 \pm 22.44$ \\
\hline Sameer et al ${ }^{11}$ & $242 \pm 62$ & $239 \pm 61$ & $160 \pm 51$ & $151 \pm 68$ \\
\hline Present study & $224.19 \pm 69.81$ & $214.9 \pm 80.87$ & $177.96 \pm 100.88$ & $143.49 \pm 67.23$ \\
\hline
\end{tabular}


eclampsia and eclampsia $(\mathrm{p}=0.319,>0.05)$.

We found a gradual decrease in mean platelet count with the progression of the disease and this difference was statistically significant. The frequency of thrombocytopenia cases was directly related to the severity of the disease. (Table 4)

The mean MPV in cases was higher than the control group, however statistically (student's unpaired t-test) insignificant $(p=0.111,>0.05)$. The mean PDW was also increased in cases as compared to that in the controls and this increase in PDW was statistically significant $(p=0.001,<0.05)$. However, the Pct was decreased in cases as compared to that in the control group and this difference was statistically significant $(\mathrm{p}=0.035,<0.05)$. (Table 5)

The platelet indices in a subgroup of the cases showed a gradual increase of MPV and PDW with the severity of the disease. However, on statistical analysis (one-way ANOVA and Tukey test) this increase of MPV and PDW in subgroups of cases as compared to that in the controls was insignificant except for an increase of PDW in eclampsia which was significantly increased as compared to the controls. The Pct value in a subgroup of cases was found to decrease gradually with the progression of disease but when compared with the mean Pct in controls, this decrease in Pct in all the subgroups of cases was statistically insignificant. (Table 5)

\section{DISCUSSION}

In this study, we found maximum cases between 21-30 years of age. The younger age of occurrence of pre-eclampsia and eclampsia affirms the early age of marriage and pregnancy in our country as compared to western countries. ${ }^{7}$ Many studies also observed the gestational age in eclampsia to be more than that in severe pre-eclampsia similar to our findings, though their findings were statistically not significant. ${ }^{8-10}$ The cases of pre-eclampsia and eclampsia were more frequent in primiparous, $(61.25 \%)$ women which are in concurrence with other studies. ${ }^{11,12}$

Most of the studies observed a significant decrease in platelet count during normal pregnancy ${ }^{13-16}$, especially during the second and third trimesters. ${ }^{14}$ In our study only $12(15.0 \%)$ women showed thrombocytopenia among controls. In cases, thrombocytopenia was observed in 36 (45\%) patients and this decrease in platelet count was directly related to the severity of the disease. This gradually reduced platelet counts in patients of mild pre-eclampsia to severe preeclampsia to eclampsia were comparable to those reported by other authors. (Table 6)

The mechanism of thrombocytopenia in pre-eclampsia and eclampsia syndrome could be increased consumption of platelets with increased megakaryocytic activity to compensate for it. Platelets adhere to areas of damaged vascular endothelium resulting in secondary destruction of platelets., ${ }^{3,23}$ Platelets from severely pre-eclamptic patients showed less response than normal to a variety of aggregating agents suggesting that platelets may have undergone the previous aggregation in the microcirculalion. ${ }^{24}$

An increase in platelet size was found in patients with moderate or severe hypertension in pregnancy, even in the presence of a normal platelet count. ${ }^{25}$ Platelet larger cell ratio $(\mathrm{P}-\mathrm{LCR})$ is an indicator of circulating larger platelets $(>$ $12 \mathrm{fL}$ ) and platelet activity. ${ }^{26}$ However, this parameter was not available in the analyzer used in the present study. The platelet parameters in pre-eclampsia and eclampsia are also related to the alteration of the coagulation process between the platelet and endothelial cells. ${ }^{27}$ It has been demonstrated that plasma thrombopoietin increase in patients with preeclampsia as a major marker of platelet activity. ${ }^{28}$

Increased MPV and PDW probably reflected increased platelet turnover with decreased platelet survival time and increased destruction of platelets., ${ }^{5,10,29,30}$ Significant increase in MPV can be detected in patients' weeks before the diagnosis of pregnancy-induced hypertension $(\mathrm{PIH}){ }^{5}$ Dundar et $\mathrm{al}^{31}$ also found a significant increase in MPV which preceded the diagnosis of PIH by approximately 4.6 weeks. Similarly, Walker et al $^{29}$ observed significantly increased MPV one week before increased BP became clinically evident.

A significant increase in PDW above the normal range in preeclampsia and eclampsia revealed the continuous platelet consumption during the progression of the disease as well as activation of platelet that compensate for the decrease in the platelet count. Therefore, the PDW can play a role as a prediction marker for the severity of pre-eclampsia before the low platelet counts are observed. In addition, it can be used to predict abnormal uncontrolled platelet activation before the progression from pre-eclampsia to severe preeclampsia with complete HELLP syndrome. ${ }^{27}$

We found decreasing levels of Pct with increasing severity of disease though the relationship was statistically insignificant when compared to controls, however, Karateke et $\mathrm{al}^{32}$ found significantly low Pct levels in pre-eclamptic patients. Singh et $\mathrm{al}^{33}$ considered PDW and Pct to be the new marker for an adverse outcome in pre-eclampsia and eclampsia even in women presenting with normal platelet counts.

\section{CONCLUSIONS}

Our study results revealed that platelet indices along with platelet count can be used in the early detection of preeclampsia and eclampsia instead of relying on platelet count alone. Also, the changes in platelet indices like PDW may provide a clue towards the potential worsening of pre-eclampsia and the eclampsia status of the patient. The present study has potential areas for further research with large sample size. 


\section{Conflict of interests: None}

\section{REFERENCES}

1. Report of the national high blood pressure education program working group on high blood pressure in pregnancy. Am J ObstetGynecol 2000;183:S1-S22. Crossref

2. Maynard SE, Karumanchi SA. Angiogenic factors and pre eclampsia. Semin Nephrol. 2011;31:33-46. $\underline{\text { Crossref }}$

3. Burrows RF, Hunter DJ, Andrew M, et al. A prospective study investigating the mechanism of thrombocytopenia in preeclampsia. ObstetGynecol1987;70:334-8. Website

4. Mohapatra S, Pradhan BB, Satpathy UK, et al. Platelet estimation: its prognostic value in pregnancy induced hypertension. Indian $\mathrm{J}$ PhysiolPharmacol2007;51:160-4. Website

5. Dadhich S, Agrawal S, Soni M, et al. Predictive value of platelet indices in development of preeclampsia. J South Asian Fed ObstetGynecol2012;4:17-21. $\underline{\text { Crossref }}$

6. ACOG practice bulletin clinical management guidelines for obstetrician-gynecologists. Obstet Gynecol. 2002;100:1045-50. Crossref

7. Priyadarshini G, Mohanty RR. Assessment of coagulation profile and its correlation with severity of preeclampsia in women of Odisha. A comparative cross-sectional study. Int J Basic Appl Physiol 2014;3: 139-145. $\underline{\text { Crossref }}$

8. Jaleel A, Baseer A. Thrombocytopenia in preeclampsia: an earlier detector of HELLP syndrome. J Pak Med Assoc 1997;47:230-2. Website

9. Nazli R, Khan MA, Akhtar T, et al. Frequency of thrombocytopenia in pregnancy related hypertensive disorders in patients presenting at tertiary care hospitals of Peshawar. Khyber Med Univ J. 2012; 4:1015. Website

10. Mohammed FE, Khalil HB, Idriss MI, et al. Variations of Platelets Indices in Pregnancy Induced Hypertension. J Physio biochemMetab2013;2:1. Crossref

11. Sameer MA, Meshram DP, Deshpande SA, et al. Role of platelet count as important prognostic marker in pregnancy induced hypertension. $\mathrm{J}$ Dent Med Sci.2014;13:39-43. Crossref

12. Donthi D, Udayakumar U, ArunGopi A. Platelet indicies in pre-eclampsia and eclampsia. National Journal of Laboratory Medicine.2018:7: 1-4. Crossref

13. Shaper AG, Kear J, Macintosh DM, et al. The platelet count, platelet adhesiveness and aggregation and the mechanism of fibrinolytic inhibition in pregnancy and the puerperium. J ObstetGynaecol $\mathrm{Br}$ Commonw.1968;75:433-41. Crossref
14. Sejeny SA, Eastham RD, Baker SR. Platelet counts during normal pregnancy. J ClinPathol.1975;28:812-3. Crossref

15. Fay RA, Hughes AO, Farron NT. Platelets in pregnancy: hyperdestruction in pregnancy. Obstet Gynecol.1983;61:238-40. Website

16. Burrows RF, Kelton JG. Incidentally detected thrombocytopenia in healthy mothers and their infants. N Engl J Med.1988;319:142-5. Crossref

17. Srivastava M, Bali S, Pandey J, et al. Pregnancy induced hypertension and antithrombin-III. Indian J PatholMicrobiol1995;38:257-60. Website

18. Jambhulkar S, Shrikhande A, Shrivastava R, et al. Coagulation profile in pregnancy induced hypertension. Indian J Hematol Blood Transfus. 2001; 19: 3-5. Website

19. Vrunda JK, Shaila S. Lowered platelet count: A prognostic index in preeclampsia. J ObstetGynaecol Ind 2004; 54:235-36. Website

20. Chauhan P, Rawat U, Bisht V, et al. Comparison of coagulation profile in pre-eclamptic and eclamptic patients with normotensive pregnant patients. J Evol Med Dent Sci 2014;12:3208-15. Crossref

21. Redman CW, Bonnar J, Beilin L. Early platelet consumption in preeclampsia. Br Med J .1978;1:467-9. Crossref

22. Gari-Bai AR. Thrombocytopenia during pregnancy. Ann Saudi Med 1998 Mar-Apr;18(2):135-9. Crossref

23. O'Brien WF, Saba HI, Knuppel RA, et al. Alterations in platelet concentration and aggregation in normal pregnancy and preeclampsia. Am J ObstetGynecol1986;155:486-90. $\underline{\text { Crossref }}$

24. Whigham KA, Howie PW, Drummond AH, et al. Abnormal platelet function in pre-eclampsia. Br J ObstetGynaecol1978;85:28-32. Crossref

25. Singer CR, Walker JJ, Cameron A, et al. Platelet studies in normal pregnancy and pregnancy-induced hypertension. Clin Lab Haematol1986;8:27-32. Crossref

26. Budak YU, Polat M, Huysal K. The use of platelet indices, plateletcrit, mean platelet volume and plateletdistribution width in emergency non-traumatic abdominal surgery: A systematic review. Biochemia Medica.2016;26:178-93. $\underline{\text { Crossref }}$

27. Yang SW, Cho SH, Kwon HS, et al. Significance of the platelet distribution width as a severity marker for the development of preeclampsia. Eur J ObstetGynecolReprod Biol.2014;175:107-11. Crossref

28. Frölich MA, Datta S, Corn SB. Thrombopoietin in normal pregnancy and preeclampsia. Am J Obstet Gynecol.1998;179:100-4. Crossref

29. Walker JJ, Cameron AD, Bjornsson S, et al. Can platelet volume 
predict progressive hypertensive disease in pregnancy? Am J Obstet Gynecol.1989;161:676-9. Crossref

30. Vamseedhar A, Srinivasa K, Santhosh K, et al . Evaluation of platelet indices and platelet counts and their significance in pre-eclampsia and eclampsia.Int J Biol Med Res. 2011;2:425-428. Website

31. Dundar O, Yoruk P, Tutuncu L et al. Longitudinal study of platelet size changes in gestation and predictive power of elevated MPV in development of pre-eclampsia. Prenat Diagn.2008;28:1052-56. Crossref
32. Karateke A, Kurt RK, Baloğlu A. Relation of platelet distribution width (PDW) and platelet crit (PCT) to preeclampsia. Ginekol Pol. 2015;86:372-5. Crossref

33. Singh A, Varma R. Role of Platelet Distribution Width (PDW) and Plateletcrit in the Assessment of Nonthrombocytopenic Preeclampsia and Eclampsia. J Obstet Gynaecol Ind. 2018;68:289-93. Crossref 